within 200 metres of a shaft that had been used to inject fluid underground for 18 years. The authors conclude that changes in ground stress as the fluid built up probably caused the faults to fail.

Wastewater injections are known to have triggered earthquakes before, but this is the largest that has been tied to the practice so far, the authors say. They suggest that even a relatively small volume of fluid can lead to significant quakes many years down the line.

Geology http://dx.doi.

org/10.1130/G34045.1 (2013)

\section{METABOLIS \\ Butterflies that live fast, die old}

Butterflies with speedier metabolisms may live longer.

Kristjan Niitepõld at Stanford University in California and Ilkka Hanski at the University of Helsinki measured the energy expenditure of Glanville fritillary butterflies (Melitaea cinxia, pictured) by placing them in chambers and recording their carbon dioxide output. Every few days, the butterflies were forced to fly in the chambers for 10-minute stretches. Butterflies with the highest rates of $\mathrm{CO}_{2}$ production lived the longest. Field experiments in which butterflies were released and recaptured showed the same pattern. Peak metabolic rate during flight could explain up to $33 \%$ of lifespan variation.

Such results are at odds with the generalization that faster metabolisms accelerate ageing and contribute to early death.

J. Exp. Biol. 216, 1388-1397 (2013)

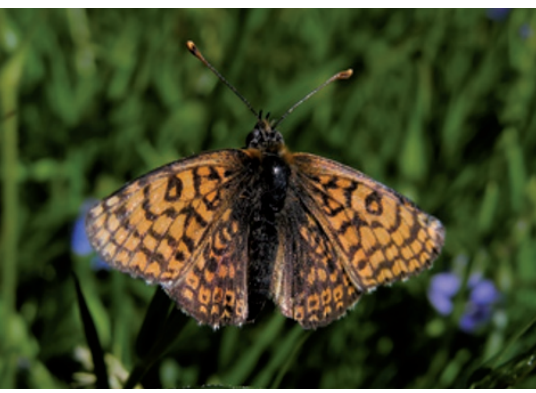

CANCER BIOLOGY

\section{Targeting cancer metabolism}

Compounds that inhibit mutated metabolic enzymes may shift cancer cells into a more benign state.

Mutations in two

metabolic genes - IDH1

and $\mathrm{IDH} 2$ - drive the growth of some tumours. Katharine Yen at Agios

Pharmaceuticals in

Cambridge, Massachusetts, Ingo Mellinghoff at the Memorial Sloan-Kettering Cancer Center in New York and their colleagues found a compound that selectively inhibits a mutated form of the IDH1 protein. In cells that carry these mutations, the inhibitor blocked formation of a cancer-associated metabolite. The compound also delayed cell growth and prompted differentiation.

Another team led by Yen designed a compound that inhibits mutated IDH 2 protein. In human leukaemia cells that bear this mutation, the compound reduced accumulation of the metabolite and prompted the cells to differentiate and mature, a transition thought to prevent cancerous growth. Science http://dx.doi. org/10.1126/science.1234769; http://dx.doi.org/10.1126/ science.1236062 (2013)

Prions prompt
multicellularity

Prions, pathogens that trigger catastrophic chain reactions of misfolded proteins in various diseases, can help yeast to survive in harsh conditions.

Yeast assume complex multicellular structures when resources are scarce, such as long-branching stalks when cells are starved of nitrogen, or ridges when fermentable carbon is in short supply. Researchers led by Randal Halfmann at the University of Texas Southwestern Medical Center in Dallas report that

COMMUNITY CHOICE

The most viewed papers in science

\title{
SINGLE-MOLECULE DYNAMICS
}

\section{Cell motors wobble to binding sites}

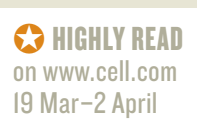

Improved high-speed imaging of single molecules shows protein motors use random motions to clamber towards their targets.

When muscles contract or cells divide, the necessary movements depend on foot-like projections of the protein myosin 'stepping' their way to binding sites on strands of the protein actin. Researchers led by Yale E. Goldman at the University of Pennsylvania in Philadelphia attached a dye to a myosin subunit, then used superfast switching of polarized light from multiple directions to take microsecond-scale snapshots that revealed the subunit's orientation and rotations. After detaching from one binding site, myosin takes a forward step that propels it only about two-thirds of the distance towards the next site. Wild gyrations get it the rest of the way. The group is now using the same technique to reveal the dynamics of molecular motors involved in processes such as protein synthesis.

Biophys. J. 104, 1263-1273 (2013)

such adaptive formations occur when a protein called Mot3 forms prions, drastically changing its shape and causing other Mot3 proteins to convert to this state. The researchers show that a non-fermentable carbon source such as ethanol induces Mot3 to form prions, and a lack of oxygen eliminates them. Thus, prions can mediate how yeast cells act cooperatively in response to their environment.

Cell 153, 153-165(2013)

\section{HYDROLOGY More rain for the Central Plains}

Climate change has altered the water cycle in the Upper Mississippi River Basin, producing rainier summers that send more runoff into the river (pictured).

Chris Frans at the University of Washington in Seattle and his team studied data from 1918 to 2007 and report that increasing precipitation during July and August, especially in the northwestern part of the region, raised stream flows in the Upper Mississippi.

Hydrological modelling

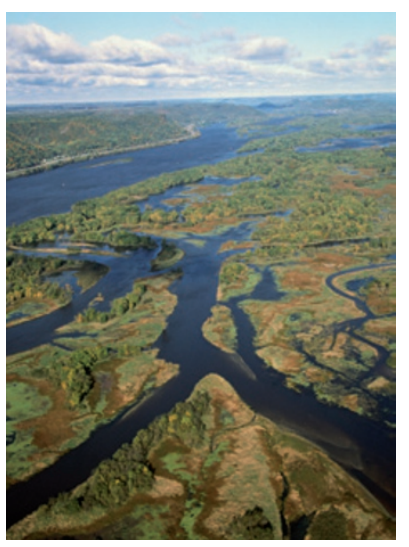

showed that although an expansion in the amount of land cleared for agriculture did increase runoff in some parts of the basin, these changes were not enough to explain the overall trend.

The findings suggest that climate change could hamper efforts to reduce the flow of nitrogen-rich runoff from the river into the Gulf of Mexico, where the nutrients create lowoxygen 'dead zones'.

Geophys. Res. Lett. http://dx.doi. org/10.1002/grl.50262 (2013).

\section{$\rightarrow$ NATURE.COM}

For the latest research published by Naturevisit:

www.nature.com/latestresearch 